Assiut Scientific Nursing Journal

http://asnj.journals.ekb.eg

http://www.arabimpactfactor.com

\title{
Effect of Implementing Teaching Program on nurses' Performance Regarding Hypoxia for Critically Ill Patients
}

\author{
Marwa Mohamed Thabet ${ }^{1}$, Mona Aly Mohamed ${ }^{2}$ \& Ghada Shalaby Khalaf $^{3}$. \\ 1. Specialist Nursing in El-Azhar University Hospital, Egypt. \\ 2. Assistant Professor of Critical Care Nursing Department Faculty of Nursing, Assiut University, Egypt. \\ 3. Lecture of critical care Nursing Department Faculty of Nursing, Assuit University, Egypt.
}

\begin{abstract}
Introduction: Hypoxemia is a common finding among critically ill patients irrespective of their underlying diagnosis. this study Aimed to evaluate the Effect of implementing teaching program on nurses' performance regarding hypoxia for critically ill patients. Design: Quasi experimental design was used in the current study. A convenience sampling of 30 nurses participated in this study. Two tools ;I were utilized knowledge assessment' questionnaire and observational checklist. Method; The teaching program was conducted over 10 repeated lectures during different working morning shifts in an average of 6 sessions per week for one month; each lecture was taking about 1.5 hours. The instructional program included presentation and watching some educational videos for the practical skills related to care of hypoxia. Results: the results revealed that nurses had lack of knowledge and practices regarding hypoxia in the critical care department, however, the hypoxia teaching program showed a positive impact in improving nurses' knowledge and practice regarding hypoxia. Conclusion: The designed instructional program was having an effective, sustainable impact on improving nurses' knowledge and practice regarding hypoxia in the critical care department. Recommendations: Implementation of continuous education programs regarding hypoxia can play a part in supporting clinical practice.
\end{abstract}

\section{Keywords: Critically Ill, hypoxia, Nurses' performance \& Teaching Program.}

\section{Introduction}

Oxygen is a vital component for all cellular activity and is, therefore, necessary to sustain life neurons, cardiomyocytes, and renal tubular cells in particular, are sensitive to sudden reductions in oxygen supply and are unable to survive prolonged periods of hypoxia (Amin et al., 2018).

Hypoxia may indicate presence of critical conditions where immediate oxygen therapy is required. Oxygen therapy is essential in clinical states of respiratory failure such as pneumonia, severe asthma, chronic bronchitis, myocardial infarction and postoperative states (Scala \& Pisani, 2018).

There are several types of hypoxia: Hypoxic hypoxia or generalized hypoxia, this refers to hypoxia resulting from an inadequate saturation of blood oxygen due to a reduced supply of oxygen in the air, decreased lung ventilation or respiratory disease. Anemic hypoxia this refers to when the capacity of the blood to carry oxygen is reduced and inadequate levels of oxygen are there forecirculated around the body . Histotoxic hypoxia this refers to when oxygen is delivered to the tissues but they fail to utilize it effectively because the cells are damaged and cannot extract and absorb oxygen from circulating blood. Stagnant hypoxia this arises from a decrease in blood flow preventing adequate blood supply to tissues, heart attack, heart failure, or cardiac arrest for example can slow the circulating of blood meaning inadequate oxygen is delivered to important tissues and organs (Rupp et al., 2019).

The major causes of hypoxia are anemia and decreased amount of oxygenated hemoglobin, carbon monoxide poisoning where the receptors that usually carry oxygen are blocked by the carbon monoxide and the use of certain medications which can alter the receptors present on red blood cells and affect their ability to carry oxygen overuse of alcohol or drugs, heart attack, heart failure or cardiac arrest for example can slow the circulating of blood meaning inadequate oxygen is delivered to important tissues and organs (Rose et al., 2017).

Hypoxia should be detected at an early stage so as to prevent serious consequences. Pulse oximetry and ABG are commonly used to obtain a rapid and continuous assessment of oxygenation. Pulse oximeter is a simple non-invasive, and reliable method to detect it and also for proper monitoring of oxygen therapy after diagnosis of hypoxia. Therefore, it should be included in the daily monitoring chart of all the admitted patients (Graham \& Unger 2018). 
The role of nurse in case of hypoxia in the first step give the patient adequate supply of oxygen by Oxygen delivery devices, Asses for changes in orientation and behavior, assess skin color for development of cyanosis, provide supplement via $100 \%$ O 2 Non rebreathe mask, prepare the patient for intubation, assess for signs of hypoxemia, and place the patient on continuous pulse oximeter, position patient with head of bed 45 degree (Wadia et al., 2020).

The nurse should, also, assist patient with coughing and deep breathing techniques, pace activities and provide rest periods to prevent fatigue. An important part of the nurse's role is to assess for early signs of hypoxia and decide whether there is a need for supplemental oxygen .However, delaying oxygen administration because of the need for a medical order may significantly affect the patient's outcome (Lin et al., 2019).

\section{Significance of the study}

Patients admitted to critical care units susceptible to hypoxia according to disease such as respiratory disease, cardiac disease and neurological disease because failure in the function of this system will lead to decreased infusion of blood to the tissues or decreased oxygen delivery to the tissues and hypoxia occur. So the nurses should be good orientated about what the mean of hypoxia, types, signs and symptoms, causes and nursing role for patients with hypoxia.

Statistics in CCU at EL-Azhar university hospital revealed that patients admitted with hypoxia during the year of 2017 ranged about 10 patient's

The nursing teaching program provides a comprehensive plan that demonstrates the feasibility of the program and ensures that nurses are able to meet the applicable standards and competencies. The nursing teaching program provides its content that ensures receive the theoretical and clinical practice experiences required to meet the applicable standards and competencies. The program provides quality to nurses in order to meet the applicable standards and competencies. The nursing teaching program has formal systems and processes in place to measure nursing performance as well as program effectiveness (Standards for Nursing Teaching Programs, 2018). Aim of the study

The aim of this study aim was to evaluate effect of implementing hypoxia teaching program on nurses' performance of critical care nurses at EL- Azhar University Hospitals and Assiut university hospital.

Research hypothesis

The following research hypothesis was formulated.
1. The nurses' post mean knowledge scores of nurses will be higher than pre mean knowledge scores.

2. The nurses' post mean performance scores will be higher than the pre performance scores.

3. Appositive correlation between nurses' knowledge and practice regarding hypoxia.

4. Independent variable (teaching program ).

5. Dependent variable ( hypoxia for critically ill patient).

\section{Subject and methods}

\section{Research design:}

Quasi - experimental (time series) design was used in the current study where the nurses, s sample served as their own control (single group study).

Setting

The study was conducted in the coronary care unit (CCU) and general ICU at Assiut university hospital and coronary care unit (CCU) at $\mathrm{Al}$ Zahar university hospital.

Subjects:

A convenience sampling of thirty nurses (working in general intensive care unit and coronary care unit at Assiut university hospital) were participate in this study and nurses working in coronary care unit at $\mathrm{Al}$ zahar university hospital.

\section{Study tools}

Two tools were utilized for collecting data:

Tool(I): Nurses' questionnaire structured interview:

A questionnaire sheet was developed by the researcher based on the review of current related literature. The overall purpose of this questionnaire was to assess the nurse's knowledge about hypoxia.

It inclued of two parts:

Part 1: Demographic characteristics of the nurses

It was developed by the researchers to assess the nurses' demographic data e. g age, marital status, qualification, years of experience and previous training opportunities about hypoxia.

\section{Part 2: knowledge assessment sheet}

This part comprised multiple choice questions related to the following categories:

This include 5 items:

Item 1 consist 10 question about anatomy and physiology of respiratory system.

Item 2 consist 10 question about definition, causes and types of hypoxia.

Item 3 consist 5 question about symptoms, signs and effect of hypoxia on body parts.

Item 4 consist 5 question about diagnosis of hypoxia. Item 5 consist 5 question about treatment and role of the nurse of hypoxia. 
Scoring system of nurse's knowledge assessment tool

- This includes 35 questions, Scores assigned to each item are between 0 and 1 points as follows; (incorrect and correct) respectively .

- According to range of total scores lie between 0-35. Nurse's knowledge was classified as:

- $\quad$ Satisfactory knowledge $\geq 65 \%$

- Unsatisfactory knowledge $\leq 65$

Tool 2: observational checklist

This observational checklist sheet was developed by the researcher based on the review of current related literature. The overall purpose of this observational checklist was to assess the nurse's practice about care of hypoxia It was consisting of three checklist: oxygen theraby. 2- pulse oximetery. 3- ABG items of each checklist as follows:

this include 3 items:

item 1 consist 17 steps about oxygen therapy.

Item 2 consist 15 steps about pulse oximetery.

Item 3 consist 25 steps about ABG.

Scoring system of nurses practice assessment tool

Regarding observational checklist: for the nurses this part that uses Likert's scale. Scores assigned to each item are between 0 and 3 points as follows; (not done, inapplicable, done in correct and done correct). According to range of total scores were classified as: unsatisfactory practice if their total score was $\leq 65 \%$ and were classified as satisfactory practice was $\geq 65 \%$ The researchers constructed and tested the tools and the instructional program of the study.

\section{Tools Validity and reliability}

Content validity, for both knowledge assessment questionnaire and the observational checklist, was checked by a panel of 5 experts specialized in critical care nursing and critical care medicine. The necessary modifications were done.

The reliability of the knowledge assessment questionnaires and the observational checklist was measured using Cronbach's alpha test and the values of Cronbach's alpha were (0.90) and (0.88) respectively.

\section{Pilot Study}

A pilot study was carried out on three nurses $(10 \%)$ from the study subjects to test the clarity, applicability, feasibility \& relevance of the tools used and to determine the needed time for the application of the study tools. Modifications on tools and program contents were done and the 3 nurses were included into the final study sample

\section{Procedure}

The study was conducted on 3 phases (preparatory, implementation and evaluation phases).

\section{1-The preparatory phase}

The researcher reviewed the related materials, recent medical textbooks and literature extensively.
The researcher searched the relevant studies on regional and global levels and searching process included libraries of local universities, regional and global electronic web sites, like Pubmed, Cochrane, Medscape, Medline and (nursing and critical text books, journals internet resources, power point presentation) about hypoxia how to diagnosis and management.

An official permission to conduct the study was obtained by the researcher from the head of the coronary and general intensive care unit department as well as the hospital nursing director after explaining the aim and nature of the study.

The steps of developing the program:

- Starting the program general and specific objectives.

- Planning the program: the content of the program were arranged into six educational sessions in addition to the preliminary one.

The content of the program covered two parts related to

- Knowledge about hypoxia and its nursing management

- Performance of specific procedures required for diagnosis of patients with hypoxia such as pulse oximeter, ABG and hypoxia management such as oxygen therapy and intubation.

2-The implementation phase

Data collection was carried out from "November 2018 until "March 2019

The first pre-test sheet was distributed to collect participants' socio-demographic data and to assess their knowledge regarding hypoxia using the questionnaires (tool I) for was 40 minutes.

the result of sheet was considered as pretest assessment and as a base line data for letter comparison with further one post implementation.

Every nurse was interviewed at break time and during minimal work load activities to collect data, mainly in the morning shift.

At the same time and over many visits during the morning shift, the researcher was observed the nurses during their work to fill out the observational checklist (tool II).

The second administration of the questionnaire was carried out immediately after implementation of the program to identify the effect of implementation of program on nurse's knowledge .

Learning environment

The program was conducted in the nursing room of coronary care unit at Assiut university hospital and at Al azhar university hospital.

Teaching methods

Lecture, discussion, video, power point and demonstration were the teaching methods used. 


\section{Arranging the sub group}

Since it was difficult to meet all nurses at the same time for program implementation the total sample was divided into (10) sup group included (3) nurses each from different work places and years of experiences.

The instructional program was conducted over 10 repeated lectures during different working morning shifts in an average of 6 sessions per week for one month; each lecture was taking about 1.5 hours. The instructional program included presentation and watching some educational videos for the practical skills related to care of hypoxia.

\section{Session of the program}

Preliminary session

- At the beginning of program the objectives, contents as well as time schedule of the program were explained by the researcher for the participant to attain their active participation and cooperation during implementation of the program. They were reassured about the confidentiality of their responses and that it has no effect on their annual evaluation.

- In this session the researcher met the participants and explained the objectives, contents and evaluation of the program.

\section{Session 1 included}

Anatomy and physiology of the respiratory system , definition of hypoxia ,types and causes.

\section{Session 2 included}

Signs and symptoms, effect of hypoxia on body organs ,complication of hypoxia and its management.

\section{Session 3 included}

Nursing role for hypoxic patients.

\section{3-The Evaluation phase}

Each lecture was evaluated by the participants at its end separately, so the studied nurses clarified their feelings and opinions toward the lecture provided and the performance in general using the evaluation form. Post-test evaluation of nurses' knowledge and practice was conducted immediately after the teaching program using the same previous mentioned tools (questionnaire and observational checklist).

The nurses were assessed during their work in the morning shift, and determine score for assessment the nurses' knowledge and practice were classified as: Satisfactory $\geq 65 \%$ or unsatisfactory $<65$.

\section{Ethical consideration}

- Research proposal was approved from ethical committee in the faculty of nursing.

- There is no risk for study subject during application of the research.

- The study was following common ethicalprinciples in clinical research.
- Informed consent was obtained from patients or guidance that is willing to participate in the study after explaining the nature and purpose of the study.

- Confidentiality and anonymity was assured.

- Nurses and patients have the right to refuse to participate and or with draw from the study without any rational any time.

- Patient privacy was considered during collection of data.

\section{Statistical analysis}

The data were tested for normality using the Anderson-Darling test and for homogeneity variances prior to further statistical analysis. Categorical variables were described by (n, \%), where continuous variables described by mean and standard deviation (Mean, SD). Chi-square test was used to compare between categorical variables where compare between continuous variables by $\mathbf{t}$ test. A two-tailed $\mathbf{p}<\mathbf{0 . 0 5}$ was considered statistically significant. We are used person Correlation to Appear the Association between scores .All analyses were performed with the IBM SPSS 20.0 software. 


\section{Results}

Tool 1: Nurses' questionnaire sheet

Table(1): Distribution of demographic characteristics of the studied nurses $n=30$.

\begin{tabular}{|c|c|c|}
\hline Demographic characteristics & $\mathbf{n}$ & $\%$ \\
\hline \multicolumn{3}{|l|}{ Hospital } \\
\hline Al-Zahra university hospital & 5 & 16.7 \\
\hline Assiut university hospital & 25 & 83.3 \\
\hline \multicolumn{3}{|l|}{ Age } \\
\hline From 18 to less than 27 years & 25 & 83.3 \\
\hline From $27-38$ years & 5 & 16.7 \\
\hline Mean \pm SD & \multicolumn{2}{|c|}{$24.80 \pm 4.34(18-38)$} \\
\hline \multicolumn{3}{|l|}{ Gender } \\
\hline Female & 30 & 100.0 \\
\hline \multicolumn{3}{|l|}{ Residence } \\
\hline Rural & 23 & 76.7 \\
\hline Urban & 7 & 23.3 \\
\hline \multicolumn{3}{|l|}{ Experience year } \\
\hline From 1 to less than 3 years & 20 & 66.7 \\
\hline From 3-5 years & 9 & 30.0 \\
\hline More than 10 years & 1 & 3.3 \\
\hline \multicolumn{3}{|l|}{ Marital } \\
\hline Single & 19 & 63.3 \\
\hline Married & 11 & 36.7 \\
\hline \multicolumn{3}{|l|}{ Level of nurse's education: } \\
\hline Diploma degree & 2 & 6.7 \\
\hline Technical institute & 25 & 83.3 \\
\hline Baccalaureate degree & 3 & 10.0 \\
\hline \multicolumn{3}{|l|}{ Occupation } \\
\hline Head nurse & 3 & 10.0 \\
\hline Bed side nurse & 27 & 90.0 \\
\hline \multicolumn{3}{|l|}{ previous training courses about hypoxia } \\
\hline Yes & 6 & 20.0 \\
\hline No & 24 & 80.0 \\
\hline \multicolumn{3}{|l|}{ What kind of care unit do you work with? } \\
\hline Coronary care unit & 17 & 56.7 \\
\hline Intensive care unit & 13 & 43.3 \\
\hline
\end{tabular}




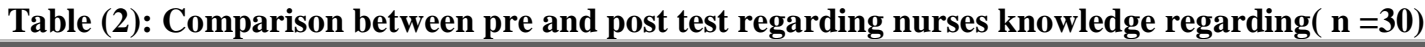

\begin{tabular}{|c|c|c|c|c|c|}
\hline \multirow{2}{*}{ Nurses knowledge } & \multicolumn{2}{|c|}{$\operatorname{Pre}(n=30)$} & \multicolumn{2}{|c|}{$\operatorname{Post}(n=30)$} & \multirow[t]{2}{*}{ P. value } \\
\hline & n. & $\%$ & n. & $\%$ & \\
\hline \multicolumn{6}{|l|}{ anatomy and physiology of respiratory } \\
\hline Anatomical components of the respiratory system & 25 & 83.3 & 30 & 100 & $0.020 *$ \\
\hline $\begin{array}{l}\text { longest part of the respiratory system that looks like a tube and measures about } 5 \\
\text { inches in length, so what is it }\end{array}$ & 23 & 76.7 & 29 & 96.7 & $0.023 *$ \\
\hline that smaller in size and contain fewer lobes & 26 & 86.7 & 30 & 100 & $0.038 *$ \\
\hline Functions of the respiratory system & 25 & 83.3 & 30 & 100 & $0.020 *$ \\
\hline The percentage of oxygen in the air & 23 & 76.7 & 30 & 100 & $0.005 * *$ \\
\hline $\begin{array}{l}\text { the most accurate definition of the total amount of oxygen delivered to the tissues } \\
\text { per minute, away from the blood flow }\end{array}$ & 12 & 40 & 29 & 96.7 & $<0.001 * *$ \\
\hline $\begin{array}{l}\text { the most accurate definition of the total amount of oxygen that tissues consume } \\
\text { per minute }\end{array}$ & 15 & 50 & 29 & 96.7 & $<0.001 * *$ \\
\hline the pathogens that affect the rate of metabolism and oxygen consumption & 26 & 86.7 & 29 & 96.7 & $0.161 \mathrm{NS}$ \\
\hline the oxygen delivery from capillaries to a cell depend on & 19 & 63.3 & 30 & 100 & $<0.001 * *$ \\
\hline \multicolumn{6}{|l|}{ Hypoxia ( definition, causes and types) } \\
\hline Definition of hypoxia & 14 & 46.7 & 30 & 100 & $<0.001 * *$ \\
\hline Definition of hypoxemia & 19 & 63.3 & 30 & 100 & $0.010^{*}$ \\
\hline the main causes of hypoxia in the blood & 20 & 66.7 & 28 & 93.3 & $<0.001 * *$ \\
\hline The types of hypoxia in cells include the following except & 15 & 50 & 30 & 100 & $<0.001 * *$ \\
\hline what occurs when there is a small amount of oxidized blood reaching the tissues & 9 & 30 & 29 & 96.7 & $0.020 *$ \\
\hline The meaning of having a lack of oxygen in the cells & 25 & 83.3 & 30 & 100 & $0.015^{*}$ \\
\hline The reasons for the lack of oxygen that occurs in the heart muscle are & 19 & 63.3 & 27 & 90 & $<0.001 * *$ \\
\hline The accumulation of carbon dioxide in the blood means & 12 & 40 & 30 & 100 & $<0.001 * *$ \\
\hline \multicolumn{6}{|l|}{ Hypoxia ( symptoms, signs and effect on body parts) } \\
\hline first sign of a lack of oxygen in the cells & 3 & 10 & 28 & 93.3 & $<0.001 * *$ \\
\hline The last sign of hypoxia in cells includes the following except & 5 & 16.7 & 30 & 100 & $<0.001 * *$ \\
\hline The mechanism that result from A lack of oxygen in the cells & 11 & 36.7 & 30 & 100 & $0.020 *$ \\
\hline What is the effect of hypoxia on cells & 18 & 60 & 26 & 86.7 & $<0.001 * *$ \\
\hline The effect of hypoxia in cells on heart rate & 16 & 53.3 & 30 & 100 & $0.010^{*}$ \\
\hline \multicolumn{6}{|l|}{ Hypoxia ( diagnosis ) } \\
\hline first method used to measure the percentage of oxygen in the blood is & 24 & 80 & 30 & 100 & $0.150 \mathrm{NS}$ \\
\hline $\begin{array}{l}\text { Another method used to measure the level of oxygen in the blood is by drawing an } \\
\text { arterial sample of the patient }\end{array}$ & 28 & 93.3 & 30 & 100 & $<0.001 * *$ \\
\hline $\begin{array}{l}\text { One of the components of the result of analyzing the ratio of gases is gases in the } \\
\text { blood except }\end{array}$ & 17 & 56.7 & 29 & 96.7 & $0.038 *$ \\
\hline The normal percentage of oxygen in the blood ranges between & 26 & 86.7 & 30 & 100 & $<0.001 * *$ \\
\hline When the percentage of carbon dioxide in the blood rises, that means & 12 & 40 & 30 & 100 & $<0.001 * *$ \\
\hline \multicolumn{6}{|l|}{ treatment and role of the nurse } \\
\hline $\begin{array}{l}\text { Dysfunctions that occur in the acid base that are explained by analyzing the } \\
\text { measurement of blood gases are they }\end{array}$ & 6 & 20 & 30 & 100 & $<0.001 * *$ \\
\hline the places where the clip used to measure the percentage of oxygen is placed & 2 & 6.7 & 30 & 100 & $0.038 *$ \\
\hline The reason of choosing ear loop to measure the percentage of oxygen & 26 & 86.7 & 30 & 100 & $0.001 * *$ \\
\hline the first thing that a nurse should do when hypoxia occurs & 20 & 66.7 & 30 & 100 & $<0.001 * *$ \\
\hline the different methods of giving oxygen to a person with a lack of oxygen & 12 & 40 & 30 & 100 & $<0.001 * *$ \\
\hline
\end{tabular}

Chi -square test * Statistically significant difference $(p<0.05)$, ** Statistically significant difference ( $p<0.01)$

NS:- Not significant 
Tool 2: Observational checklist sheet

Table (7): The distribution of the studied nurses' practice regarding oxygen therapy ( $\mathrm{n}=30$ ).

\begin{tabular}{|c|c|c|c|c|c|c|c|}
\hline & \multicolumn{3}{|c|}{$\operatorname{pre}(\mathbf{n}=30)$} & \multicolumn{3}{|c|}{$\operatorname{post}(n=30)$} & \multirow{4}{*}{ P. value } \\
\hline & \multirow[b]{2}{*}{ Not done } & \multicolumn{2}{|c|}{ done } & \multirow[b]{2}{*}{ Not done } & \multicolumn{2}{|c|}{ done } & \\
\hline & & $\begin{array}{c}\text { un } \\
\text { correctly }\end{array}$ & Correctly & & $\begin{array}{c}\text { un } \\
\text { correctly }\end{array}$ & correctly & \\
\hline & $\mathbf{n}(\%)$ & No(\%) & $\mathbf{n}(\%)$ & $\mathrm{n}(\%)$ & $\mathrm{n}(\%)$ & $\mathbf{n}(\%)$ & \\
\hline hand hygiene & $16(53.3)$ & $12(40)$ & $2(6.7)$ & $0(0)$ & $1(3.3)$ & $29(96.7)$ & $<0.001 * *$ \\
\hline Check room for precautions & $29(96.7)$ & $0(0)$ & $1(3.3)$ & $4(13.3)$ & $0(0)$ & $26(86.7)$ & $<0.001 * *$ \\
\hline Introduce yourself to patient & $30(100)$ & $0(0)$ & $0(0)$ & $5(16.7)$ & $0(0)$ & $25(83.3)$ & $<0.001 * *$ \\
\hline Check patients name band & $28(93.3)$ & $0(0)$ & $2(6.7)$ & $6(20)$ & $0(0)$ & $24(80)$ & $<0.001 * *$ \\
\hline Explain process to the patient & $30(100)$ & $0(0)$ & $0(0)$ & $4(13.3)$ & $0(0)$ & $26(86.7)$ & $<0.001 * *$ \\
\hline Use listening and questioning skills & $27(90)$ & $0(0)$ & $3(10)$ & $13(43.3)$ & $0(0)$ & $17(56.7)$ & $<0.001 * *$ \\
\hline Listen to patient cuses & $29(96.7)$ & $0(0)$ & $1(3.3)$ & $13(43.3)$ & $0(0)$ & $17(56.7)$ & $<0.001 * *$ \\
\hline Ensure patients privacy & $26(86.7)$ & $0(0)$ & $4(13.3)$ & $2(6.7)$ & $0(0)$ & $28(93.3)$ & $<0.001 * *$ \\
\hline Apply principles of asepsis and safety & $27(90)$ & $0(0)$ & $3(10)$ & $2(6.7)$ & $0(0)$ & $28(93.3)$ & $<0.001 * *$ \\
\hline $\begin{array}{l}\text { Complete respiratory assessment for } \\
\text { hypoxia, sao2should be greater than } \\
92 \%\end{array}$ & $9(30)$ & $3(10)$ & $18(60)$ & $0(0)$ & $2(6.7)$ & $28(93.3)$ & $0.003 * *$ \\
\hline $\begin{array}{l}\text { If a patient require oxygen therapy, } \\
\text { choose an oxygen delivery system } \\
\text { based on your patients requirements }\end{array}$ & $3(10)$ & $1(3.3)$ & $26(86.7)$ & $1(3.3)$ & $0(0)$ & $29(96.7)$ & $0.339 \mathrm{NS}$ \\
\hline $\begin{array}{l}\text { reassess your patient is } 5 \text { minutes to } \\
\text { determine the effects on the body. }\end{array}$ & $12(40)$ & $0(0)$ & $18(60)$ & $0(0)$ & $0(0)$ & $30(100)$ & $<0.001 * *$ \\
\hline $\begin{array}{l}\text { adjust } 02 \text { levels changes in } 02 \\
\text { percentages should be in } 5 \% \text { to } 10 \% \\
\text { increments }\end{array}$ & $9(30)$ & $2(6.7)$ & 19(63.3) & $0(0)$ & $0(0)$ & $30(100)$ & $0.001 * *$ \\
\hline $\begin{array}{l}\text { If hypoxia continues contact } \\
\text { respiratory therapist orphysician for } \\
\text { further orders }\end{array}$ & $26(86.7)$ & $0(0)$ & $4(13.3)$ & $1(3.3)$ & $0(0)$ & $29(96.7)$ & $<0.001 * *$ \\
\hline $\begin{array}{l}\text { Management of hypoxia are oral } \\
\text { suctioning, position changes and deep } \\
\text { breathing and coughing exercises }\end{array}$ & $4(13.3)$ & $1(3.3)$ & $25(83.3)$ & $0(0)$ & $1(3.3)$ & $29(96.7)$ & $0.117 \mathrm{NS}$ \\
\hline $\begin{array}{l}\text { performs a respiratory assessment } \\
\text { every two to four hours to monitor } \\
\text { need for supplemental oxygen }\end{array}$ & $18(60)$ & $1(3.3)$ & 11(36.7) & $1(3.3)$ & $1(3.3)$ & 28(93.3) & $<0.001 * *$ \\
\hline $\begin{array}{l}\text { Assess the patients skin where the } \\
\text { oxygen device comes into contact } \\
\text { with the patient }\end{array}$ & $18(60)$ & $1(3.3)$ & 11(36.7) & $1(3.3)$ & $1(3.3)$ & $28(93.3)$ & $<0.001 * *$ \\
\hline
\end{tabular}


Table (8): The distribution of the studied nurses' practice regarding pulse oximetry $(\mathrm{n}=30)$.

\begin{tabular}{|c|c|c|c|c|c|c|c|}
\hline & \multicolumn{3}{|c|}{$\operatorname{pre}(n=30)$} & \multicolumn{3}{|c|}{$\operatorname{post}(n=30)$} & \multirow{4}{*}{ P.value } \\
\hline & \multirow[b]{2}{*}{ Not done } & \multicolumn{2}{|c|}{ done } & \multirow[b]{2}{*}{ Not done } & \multicolumn{2}{|c|}{ done } & \\
\hline & & $\begin{array}{c}\text { un } \\
\text { correctly }\end{array}$ & correctly & & $\begin{array}{c}\text { un } \\
\text { correctly }\end{array}$ & Correctly & \\
\hline & $\mathrm{n}(\%)$ & $\mathbf{n}(\%)$ & $\mathrm{n}(\%)$ & $\mathrm{n}(\%)$ & $\mathbf{n}(\%)$ & $\mathrm{n}(\%)$ & \\
\hline Sanitize your hands & $20(66.7)$ & $10(33.3)$ & $0(0)$ & $1(3.3)$ & $6(20)$ & $23(76.7)$ & $<0.001 * *$ \\
\hline Assemble the equipment & $22(73.3)$ & $4(13.3)$ & $4(13.3)$ & $1(3.3)$ & $0(0)$ & $29(96.7)$ & $<0.001 * *$ \\
\hline $\begin{array}{l}\text { introduce your self and explain } \\
\text { the procedure }\end{array}$ & $28(93.3)$ & $2(6.7)$ & $0(0)$ & $9(30)$ & $1(3.3)$ & $20(66.7)$ & $<0.001 * *$ \\
\hline Seat the patient & $24(80)$ & $2(6.7)$ & $4(13.3)$ & $4(13.3)$ & $0(0)$ & $26(86.7)$ & $<0.001 * *$ \\
\hline $\begin{array}{l}\text { Select an appropriate finger to } \\
\text { apply the probe }\end{array}$ & $3(10)$ & $2(6.7)$ & $25(83.3)$ & $3(10)$ & $0(0)$ & $27(90)$ & $0.354 \mathbf{~ N S}$ \\
\hline Observe the patients finger nail & $28(93.3)$ & $2(6.7)$ & $0(0)$ & $15(50)$ & $0(0)$ & $15(50)$ & $<0.001 * *$ \\
\hline $\begin{array}{l}\text { Check to ensure that the } \\
\text { patients finger rip is clean }\end{array}$ & $27(90)$ & $3(10)$ & $0(0)$ & $16(53.3)$ & $0(0)$ & $14(46.7)$ & $<0.001 * *$ \\
\hline $\begin{array}{l}\text { position the probe securely on } \\
\text { the fingertip as follows }\end{array}$ & $10(33.3)$ & $1(3.3)$ & $19(63.3)$ & $1(3.3)$ & $0(0)$ & $29(96.7)$ & $0.005^{* *}$ \\
\hline $\begin{array}{l}\text { Instruct the patient to remain } \\
\text { still and to breath normally }\end{array}$ & $14(46.7)$ & $3(10)$ & $13(43.3)$ & $3(10)$ & $3(10)$ & $24(80)$ & $0.006 * *$ \\
\hline $\begin{array}{l}\text { Allow several seconds for the } \\
\text { pulse oxygen saturation of the } \\
\text { blood }\end{array}$ & $0(0)$ & $0(0)$ & $30(100)$ & $0(0)$ & $0(0)$ & $30(100)$ & \\
\hline $\begin{array}{l}\text { Leave the probe in place until } \\
\text { the oximeter displays areading }\end{array}$ & $0(0)$ & $0(0)$ & $30(100)$ & $3(10)$ & $0(0)$ & $27(90)$ & $0.076 \mathrm{NS}$ \\
\hline $\begin{array}{l}\text { Remove the probe from the } \\
\text { patients finger and turn off the } \\
\text { oximeter }\end{array}$ & $1(3.3)$ & $3(10)$ & $26(86.7)$ & $0(0)$ & $0(0)$ & $30(100)$ & $0.117 \mathrm{NS}$ \\
\hline Sanitize your hands & $15(50)$ & $8(26.7)$ & $7(23.3)$ & $0(0)$ & $5(16.7)$ & $25(83.3)$ & $<0.001 * *$ \\
\hline $\begin{array}{l}\text { Chart the results in the patients } \\
\text { medical record }\end{array}$ & $0(0)$ & $0(0)$ & $30(100)$ & $0(0)$ & $0(0)$ & $30(100)$ & \\
\hline $\begin{array}{l}\text { Disconnect the cable from the } \\
\text { monitor. Disinfect the probe } \\
\text { with an antiseptic }\end{array}$ & $4(13.3)$ & $0(0)$ & $26(86.7)$ & $0(0)$ & $0(0)$ & $30(100)$ & $0.038^{*}$ \\
\hline
\end{tabular}

Chi -square test * Statistically significant difference $(p<0.05), * *$ Statistically significant difference $(p<0.01)$

NS:- Not significant 
Table (9): The distribution of the studied nurses' practice regarding ABG $\mathbf{n}=30$

\begin{tabular}{|c|c|c|c|c|c|c|c|}
\hline & \multicolumn{3}{|c|}{$\operatorname{pre}(n=30)$} & \multicolumn{3}{|c|}{$\operatorname{post}(n=30)$} & \multirow{4}{*}{ P. value } \\
\hline & \multirow[b]{2}{*}{ Not done } & \multicolumn{2}{|c|}{ done } & \multirow[b]{2}{*}{ Not done } & \multicolumn{2}{|c|}{ done } & \\
\hline & & $\begin{array}{c}\text { Not } \\
\text { correctly }\end{array}$ & correctly & & $\begin{array}{c}\text { Not } \\
\text { correctly }\end{array}$ & correctly & \\
\hline & $\mathrm{n}(\%)$ & $\mathbf{n}(\%)$ & $\mathrm{n}(\%)$ & $\mathrm{n}(\%)$ & $\mathrm{n}(\%)$ & $\mathrm{n}(\%)$ & \\
\hline Define the patient & $24(80)$ & $4(13.3)$ & $2(6.7)$ & $3(10)$ & $1(3.3)$ & $26(86.7)$ & $<0.001 * *$ \\
\hline $\begin{array}{l}\text { record the amount of oxygen the patient is } \\
\text { receiving and expiring }\end{array}$ & $27(90)$ & $0(0)$ & $3(10)$ & $4(13.3)$ & $0(0)$ & $26(86.7)$ & $<0.001 * *$ \\
\hline hand hygiene & $23(76.7)$ & $6(20)$ & $1(3.3)$ & $2(6.7)$ & $1(3.3)$ & $27(90)$ & $<0.001 * *$ \\
\hline prepare the ABG syringe & $28(93.3)$ & $0(0)$ & $2(6.7)$ & $13(43.3)$ & $1(3.3)$ & $16(53.3)$ & $<0.001 * *$ \\
\hline temporarily suspend the arterial alarms & $26(86.7)$ & $1(3.3)$ & $3(10)$ & $17(56.7)$ & $0(0)$ & $13(43.3)$ & $0.010 *$ \\
\hline locate the arterial site & $6(20)$ & $0(0)$ & $24(80)$ & $1(3.3)$ & $0(0)$ & $29(96.7)$ & $0.044 *$ \\
\hline clean the arterial site & $23(76.7)$ & $0(0)$ & $7(23.3)$ & $10(33.3)$ & $0(0)$ & $20(66.7)$ & $0.001 * *$ \\
\hline put gloves & $10(33.3)$ & $0(0)$ & $20(66.7)$ & $2(6.7)$ & $0(0)$ & $28(93.3)$ & $0.010 *$ \\
\hline $\begin{array}{l}\text { numb the area with } 1 \text { precent } \\
\text { enpinephrine- free lidocaine }\end{array}$ & $27(90)$ & $0(0)$ & $3(10)$ & $17(56.7)$ & $0(0)$ & $13(43.3)$ & $0.004 * *$ \\
\hline wait 1 to 2 minutes & $23(76.7)$ & $0(0)$ & $7(23.3)$ & $3(10)$ & $0(0)$ & $27(90)$ & $<0.001 * *$ \\
\hline clean the venipuncture with alochol swab & $25(83.3)$ & $0(0)$ & $5(16.7)$ & $16(53.3)$ & $0(0)$ & $14(46.7)$ & $0.012 *$ \\
\hline position the patient wrist & $20(66.7)$ & $0(0)$ & $10(33.3)$ & $1(3.3)$ & $0(0)$ & $29(96.7)$ & 0.000 \\
\hline $\begin{array}{l}\text { relocate the artery by placing the index or } \\
\text { middle finger over the artery to plapate } \\
\text { for its size, depth and direction. }\end{array}$ & $2(6.7)$ & $1(3.3)$ & $27(90)$ & $0(0)$ & $0(0)$ & $30(100)$ & 0.206 NS \\
\hline $\begin{array}{l}\text { puncture the skin about } 5 \text { to } 10 \mathrm{mi} \text { down } \\
\text { the lenght of }\end{array}$ & $3(10)$ & $0(0)$ & $27(90)$ & $0(0)$ & $1(3.3)$ & 29(96.7) & $0.131 \mathrm{NS}$ \\
\hline $\begin{array}{l}\text { the syringe will fill on its own due to the } \\
\text { arertial pressure }\end{array}$ & $20(66.7)$ & $0(0)$ & $10(33.3)$ & $0(0)$ & $0(0)$ & $30(100)$ & $<0.001 * *$ \\
\hline $\begin{array}{l}\text { the syringe and needle are gently pulled } \\
\text { from the puncture }\end{array}$ & $17(56.7)$ & $0(0)$ & $13(43.3)$ & $1(3.3)$ & $0(0)$ & $29(96.7)$ & $<0.001 * *$ \\
\hline $\begin{array}{l}\text { the needle must be removed form } \\
\text { syringes }\end{array}$ & $24(80)$ & $0(0)$ & $6(20)$ & $4(13.3)$ & $0(0)$ & $26(86.7)$ & $<0.001 * *$ \\
\hline $\begin{array}{l}\text { the removal of the needle will create an } \\
\text { opening for aie to infiltrate the sample }\end{array}$ & $26(86.7)$ & $0(0)$ & $4(13.3)$ & $4(13.3)$ & $0(0)$ & $26(86.7)$ & $<0.001 * *$ \\
\hline lable the sample & $0(0)$ & $0(0)$ & $30(100)$ & $2(6.7)$ & $0(0)$ & $28(93.3)$ & $0.150 \mathrm{NS}$ \\
\hline immerse the sample in an ice & $29(96.7)$ & $0(0)$ & $1(3.3)$ & $14(46.7)$ & $0(0)$ & $16(53.3)$ & $<0.001 * *$ \\
\hline $\begin{array}{l}\text { Re a check the identification bracelet with } \\
\text { the lables requsitions }\end{array}$ & $10(33.3)$ & $0(0)$ & $20(66.7)$ & $2(6.7)$ & $0(0)$ & $28(93.3)$ & $0.010 *$ \\
\hline lable the sample & $0(0)$ & $0(0)$ & $30(100)$ & $0(0)$ & $0(0)$ & $30(100)$ & - \\
\hline $\begin{array}{l}\text { check the puncture site Apply adhesive } \\
\text { bandage }\end{array}$ & $29(96.7)$ & $0(0)$ & $1(3.3)$ & $3(10)$ & $0(0)$ & $27(90)$ & $<0.001 * *$ \\
\hline remove gloves and perform hand hygiene & $19(63.3)$ & $5(16.7)$ & $6(20)$ & $0(0)$ & $3(10)$ & $27(90)$ & $<0.001 * *$ \\
\hline $\begin{array}{l}\text { thank the patient and transport the sample } \\
\text { to the laboratory }\end{array}$ & $3(10)$ & $0(0)$ & $27(90)$ & $0(0)$ & $0(0)$ & $30(100)$ & $0.076 \mathrm{NS}$ \\
\hline
\end{tabular}

Chi -square test * Statistically significant difference $(p<0.05)$, ** Statistically significant difference $(p<0.01)$ NS:- Not significant 
Table (1): Showed that; majority (83.3\%) of the studied nurses from Assiut university hospital, and their ages ranged from 18-27 years, while all of them $(100.0 \%)$ were female. More than half of them were from rural areas, their experience ranged from 1 to 3 years and single (76.7, 66.7 and $63.3 \%$ respectively). Majority $(83.3 \%)$ had technical institute and most of them $(90.0 \%)$ were bed side nurse. Majority of the studied nurses $(80.0 \%)$ did not attain any previous training courses about hypoxia and only around half (56.7\%) working at Coronary care unit.

Table (2): Showed that there was a statistically significant difference between pre and post test regarding nurses' knowledge regarding anatomy and function of respiratory system except when asked about the most accurate definition of the total amount of oxygen that tissues consume per minute. In addition the table showed a significance improvement in their knowledge after implementing teaching program regarding hypoxia for critically ill patients.

Table (3): Showed that there was a statistically significant difference between pre and post test regarding nurses' knowledge regarding (definition, causes and types of hypoxia). In addition the table showed a significance improvement in their knowledge after implementing teaching program regarding hypoxia for critically ill patients.

Table (4): Showed that there was a statistically significant difference between pre and post test regarding nurses' knowledge regarding symptoms, signs and effect of hypoxia on body parts. In addition the table showed a significance improvement in their knowledge after implementing teaching program regarding hypoxia for critically ill patients

Table (5): Showed that there was a statistically significant difference between pre and posttest regarding nurses' knowledge regarding diagnosis and treatment of hypoxia, except when asked about the first method used to measure the percentage of oxygen in the blood is. In addition the table showed a significance improvement in their knowledge after implementing teaching program regarding hypoxia for critically ill patients.

Table (6): Showed that there was a statistically significant difference between pre and post test regarding nurses' knowledge regarding regarding treatment and role of the nurse of hypoxia. In addition the table showed a significance improvement in their knowledge after implementing teaching program regarding hypoxia for critically ill patients.

Table (7): Showed regarding the studied nurses' practice of oxygen therapy pre the program application , that all of the studied nurses (100\%) didn't introduce themselves to patient or explain process to the patient. In addition most of them did not check room for additional precautions check patients name band to confirm identification use appropropriate listening and questioning skills listen and attend to patient cuses, and apply principles of asepsis and safety $(96.7,93.3,90.0,96.7$ and $90.0 \%$ respectively). While regarding the studied nurses' practice of oxygen therapy post the program application, that majority of the studied nurses did all steps correctly. The table showed that there was a statistically significant difference between pre and post test regarding nurses' practice regarding oxygen therapy. In addition the table showed a significance improvement in their practice after implementing teaching program regarding oxygen therapy except if a patient require oxygen therapy, choose an oxygen delivery system based on your patients requirements and management of hypoxia are oral suctioning, position changes and deep breathing and coughing exercises.

Table (8): Showed regarding the studied nurses' practice of pulse oximetry pre the program application, that all of the studied nurses $(100 \%)$ correctly perform ether allow several seconds for the pulse oxygen saturation of the blood, leave the probe in place until the oximeter displays areading and chart the results in the patients medical record. But in the other hand they did not perform neither great the patient and introduce self, identify the patient and explain the procedure, seat the patient, observe the patients finger nail if the patient is wearing dark finger nail polish nor check to ensure that the patients finger rip is clean $(93.3,80.0,93.3$ and $90.0 \%$ respectively)

While regarding the studied nurses' practice of pulse oximetry post the program application, that majority of the studied nurses did all steps correctly. The table showed that there was a statistically significant difference between pre and posttest regarding nurses' practice regarding pulse oximetry. In addition the table showed a significance improvement in their practice after implementing teaching program regarding oxygen therapy except Remove the probe from the patients finger and turn off the oximeter, leave the probe in place until the oximeter displays a reading and select an appropriate finger to apply the probe use the tip of the patients index.

Table (9): Showed regarding the studied nurses' practice of $\mathrm{ABG}$ pre the program application, that all of the studied nurses (100\%) correctly label the sample. And majority of them (90\%) perform correctly either relocate the artery by placing the index or middle finger over the artery to palpate for its size, depth and direction puncture the skin about 5 to $10 \mathrm{ml}$ down the length of thank the patient and transport the sample to the laboratory. But in the other hand they did not perform neither record the amount of oxygen the patient is receiving and expiring, when 
obtaining an ABG sample, open the ABG kit and use the plunger to rid the excess heparin and air from the syringe, numb the area with 1 precent enpinephrinefree lidocaine, immerse the sample in anice, nor check the puncture site and apply adhesive bandage (90.0, 93.3, 90.0 and $96.7 \%$ respectively). While regarding the studied nurses' practice of ABG post the program application, that majority of the studied nurses did all steps correctly. The table showed that there was a statistically significant difference between pre and post test regarding nurses' practice regarding ABG. In addition the table showed a significance improvement in their practice after implementing teaching program regarding oxygen therapy except thank the patient and transport the sample to the laboratory and label the sample.

Fig(1): Comparison between pre and post test regarding the total scores of nurses' knowledge regarding hypoxia $\mathbf{n}=\mathbf{3 0}$

Figure (1): Showed that there was a statistically significant difference between pre and posttest regarding the total scores of nurses' knowledge regarding hypoxia among critical ill.

patients,. In addition the table showed a significance improvement in their knowledge (100\%) satisfactory level after implementing teaching program regarding hypoxia for critically ill patients.

Fig (2): Comparison between pre and post test regarding the total mean scores of nurses' practice regarding hypoxia related to specific procedures required for oxygen therapy, pulse oximeter and $\mathrm{ABG}$ $\mathrm{n}=30$.

Figure (2): Showed that there was a statistically significant difference between pre and post test regarding the total scores of nurses' practice regarding hypoxia among critical ill patients,. In addition the table showed a significance improvement in their practice $(100 \%)$ satisfactory level after implementing teaching program regarding hypoxia for critically ill patients.

Fig (3): Correlation between nurses' knowledge and practice pre and post test, $n=30$

Figure (3): Showed that there was no correlation between nurses' knowledge and practice pre test and showed that there was appositive correlation between nurses' knowledge and practice post test.

\section{Discussion}

From the analysis of the 35 items knowledge assessment questionnaire, the pre-post test results revealed that knowledge about hypoxia the first rank with the anatomy and physiology of respiratory system occupied the second rank; definition ,causes and types of hypoxia occupied the third rank, the definition ,causes and types of hypoxia occupied the fourth the diagnosis of hypoxia occupied while the last rank was occupied by the treatment and role of the nurse of hypoxia. The mean score of the total knowledge about hypoxia the majority of them had satisfactory level after application $(95.76 \%)$, while was nearly half $(57.92 \%)$ was unsatisfactory before the program implementation.

This study showed that there was a statistically significant difference between pre and posttest regarding the total scores of nurses' knowledge regarding hypoxia among critical ill patients. In addition the data showed a significance improvement in their knowledge satisfactory level after implementing teaching program regarding hypoxia for critically ill patients.

We cannot ignore the big percent of unsatisfactory level that may be attributed to insufficient courses related to standards nursing care for patients with bronchial asthma in their curriculum of nursing education and also insufficient in-service training. Also, this low level of knowledge may be related to lack of training sessions, no standard guidelines for managing hypoxia, work overload, lack of the desire of nurses to improve their knowledge, especially those who have been working in ICUs for several years.

Also Guo et al., (2018) mentioned that nurses' knowledge toward hypoxia is moderate and they recommended the need for in-service educational programs to develop nurses' knowledge and practice in order to fit this contemporary trend in health care.

In addition to Yousif et al., (2020) who indicated that although there was a high level of awareness towards the suitable therapy for hypoxia among medical students, but there was a poor level of general knowledge about oxygen therapy.

It can be concluded that, developing and implementing the nursing teaching program am about immediate and long term nursing management of patient with hypoxia achieved its objectives by improving nurse's knowledge. This is interpreted that the researcher had suitable learning media and material for teaching that improved nurses' knowledge.

Regarding the studied nurses' practice of oxygen therapy, that all of the studied nurses didn't introduce themselves to patient or explain process to the patient. In addition most of them did not check room for additional precautions check patients name band to confirm identification use appropriate listening and questioning skills listen and attend to patient causes, and apply principles of asepsis and safety.

Moreover, the nurses lack the efficiency of updating their practice after being and settled in the clinical environment for a longer time and possible explanation for this finding is that the workload (Mabona et al., 2019). 
This result was in divergence with AL-gabri et al., (2019) who mention that most of the nurses had proper performances regarding administrating oxygen by face mask. Establishment of training courses and workshops continues educational programs are important to ensure standard quality of nursing care.

These results disproportionate with Bunkenborg, \& Bundgaard, (2019) who found that majority of the nurses which represents had proper performances regarding administrating oxygen these might be due to nurses had a good practice about oxygen therapy. Generally, there was an improvement of nurses' total practice scores regarding administering oxygen by nasal cannula, mask and tent in addition to pulse oximetry procedure. This in concordance with Payen et al., (2019) who found in their research that; majority of the nurses which represents had proper performances regarding administrating oxygen by nasal cannula, and majority of them had proper performances regarding administrating oxygen by face mask these might be due to nurses had good practice about oxygen therapy.

Semper et al., (2016) who reported that teaching programs for nursing staff play an important role in assist in staff nurses in developing and enhancing their skills needed to provide high standards of care to their patients. This agreed with the present study as nurse's knowledge and practice improved after implementation of the nursing educational program.

Nakagami et al., (2018) were in the same line with the current study findings, their study revealed that an improvement in nurses' practice after the attendance at continuing nursing education sessions. Research findings indicated that continued nursing education programs increase knowledge, practice and can also improve attitudes.

Similarly, Farry \& Norkus, (2018) documented that nurses are not familiar with the complexities of monitoring equipment and stressed that there is an immediate need to improve nursing education in the use of oxygen therapy, pulse oximetry an ABG. So the nurse should follow the manufactory instruction to connect it properly and safely to prevent oxygen from escape. In addition, a copy of detailed instructions should be at hand to serve as a reminder of the foregoing instructions and demonstrate given by a well-informed super visor and technician.

The present showed that there was a statistically significant difference between pre and posttest regarding the total scores of nurses' practice regarding hypoxia among critical ill patients. In addition the results showed a significance improvement in their practice satisfactory level after implementing teaching program regarding hypoxia for critically ill patients.
In the same line Yousif et al., (2020) stated that a well-designed course on asthma management is an efficient scheme to improve public health nurses' knowledge and confidence on hypoxia care.

Andersen et al., (2018) reported that each organization and profession must set standards and objectives to guide individuals and practitioners in performing safe and effective care. Also not only must standards exist, but leader and managers also must see that subordinates know and understand the standards and employee must be aware that their performance will be measured in terms of their ability to meet the established standards.

Regarding the relationship between nurses' knowledge and practice regarding hypoxia. The current study demonstrated that there was a highly statistical significant difference in nurses' performance (knowledge and practice) after giving the educational program. This study was in the line with Gooch \& Roberts, (2017) who expressed that the nursing care protocol established to be effective in improving the knowledge and practice among staff nurses regarding the management of patients with hypoxia.

This result was congruent with a recent study which found that critically ill patients' management are directly influenced by nurses. Therefore, critical care nurses should be provided with the knowledge, skills, and abilities to care for this important segment of the patient population to achieve the best practice and optimal outcomes for critical patients Jayanna et al., (2016). Such structured education will improve the knowledge and practice of staff nurses. Suitable intervention packages need to be developed and inservice education need to be given periodically for the effectiveness of qualitative nursing services (Madiha, et al., 2017).

Finally, the findings of the present study supported the research hypothesis that nurses working in ICU who are exposed to teaching guidelines about hypoxia care will show high score of practice after test (posttest) than that before (pretest).

The study result revealed that all of the nurses were female, More than half of them were from rural areas, their experience ranged from 1to 3 years and single. Majority had technical institute and most of them were bed side nurse. This result in not match with Anderson et al., (2016) who reported that the majority of nurses who are working in ICU generally had bachelor degree in nursing.

In relation to attending any previous training program, the participant nurses not attaining any previous training. This might due to hospital not have staff development program.

This indicates that nurses are not prepared before graduation and the experiences of the nurses have 
been gained while working only in an intensive care unit. Therefore, in-service training program is necessary to prepare nurses to handle clinical alarm management at the postgraduate level.

This result was supported by Bunkenborg \& Bundgaard, (2019) who said that nurses who are working in the intensive care unit needs additional education to provide optimal care for patients that are oxygen therapy to prevent hypoxia. In addition to Mostafa et al., (2019) mentioned that in their study participants from nurses had never attended training courses on oxygen therapy and hypoxia.

Participants' average age was 18-27 years. It may be due to the administrators selected younger age nurses to be able to perform mainly tasks in the intensive care unit effectively and easily as their fitness were highly than older ones. This result was not in the same line with Rostamabadi et al., (2017) who found Participants' average age was 40 years $(\mathrm{SD}=$ 4.68). It may be due to the administrators selected older age nurses to work in the intensive care unit meritoriously.

\section{Conclusion}

This study aimed to evaluate effect of implementing hypoxia teaching program on performance of critical care nurses at EL- Azhar University Hospitals and Assiut university hospital.

Based on the results of the present study we concluded the following

There was a statistically significant difference between pre and post test regarding overall nurses knowledge regarding hypoxia. In addition there was a significance improvement in their knowledge after implementing teaching program regarding hypoxia for critically ill patients the majority of them had satisfactory level after application $(95.76 \%)$, while was nearly half $(57.92 \%)$ was unsatisfactory before the program implementation.

The total mean scores of nurses' practice regarding hypoxia among critical ill patients improved after implementing teaching program regarding hypoxia for critically ill patients. And majority $(85.85 \%)$ of the studied nurses totally had satisfactory level scores after education with score 97.87 degrees and there was a statistically significant difference between pre and post test regarding the total scores of nurses' practice regarding hypoxia among critical ill patients. There was appositive correlation between nurses' knowledge and practice post test.

\section{Recommendations}

On the basis of the findings of the study, the following recommendations have been made.

1. This study recommended that keep the program on knowledge and practice of critical care nurses available in all the intensive care unit.

2. In general providing training programs for new joined ICU nurse about knowledge and practice of critical care nurses in the future.

3. Reapplication of the study on a large probability of sample from different ICU is required.

\section{References}

1. AL-gabri, M., Mohammed, M., \& Mehany, M., (2019): Assessment of Nurses' Performance Regarding Care Of Chest Trauma Patients at Trauma Emergency Unit. Assiut Scientific Nursing Journal, 7(17), 121-132.

2. Allibone, E., Soares, T., \& Wilson, A., (2018): Safe and effective use of supplemental oxygen therapy. Nursing standard (Royal College of Nursing (Great Britain): 1987), 33(5), 43-50.

3. Amin, H., Dipalo, M., De Angelis, F., \& Berdondini, L., (2018). Biofunctionalized 3D nanopillar arrays fostering cell guidance and promoting synapse stability and neuronal activity in networks. ACS applied materials \& interfaces, 10(17), 15207-15215.

4. Andersen, D., Baird, S., Bates, T., Chapel, D., Cline, A., Ganesh, S., \& Jones, S., (2018): Academy of nutrition and dietetics: Revised 2017 standards of practice in nutrition care and standards of professional performance for registered dietitian nutritionists. Journal of the Academy of Nutrition and Dietetics, 118(1), 132-140.

5. Anderson, W., Puntillo, K., Boyle, D., Barbour, S., Turner, K., Cimino, J., \& Grywalski, M., (2016): ICU bedside nurses' involvement in palliative care communication: A multicenter survey. Journal of pain and symptom management, 51(3), 589-596.

6. Beane, A., Padeniya, A., De Silva, A. P., Stephens, T., De Alwis, S., Mahipala, P., \& Deshani, E., (2017): Closing the theory to practice gap for newly qualified doctors: evaluation of a peer-delivered practical skills training course for newly qualified doctors in preparation for clinical practice. Postgraduate medical journal, 93(1104), 592-596. 
7. Bunkenborg, G., \& Bundgaard, K., (2019): A mixed methods exploration of intensive care unit nurses' perception of handling oxygen therapy to critically ill patients. Intensive and Critical Care Nursing, 52, 42-50.

8. Farry, T., \& Norkus, C., (2018): Monitoring the critical patient. Veterinary Technician's Manual for Small Animal Emergency and Critical Care, 45-63.

9. Gooch, M. D., \& Roberts, E. (2017). Changing the Emergency Department's Practice of Rapid Sequence Intubation to Reduce the Incidence of Hypoxia. Advanced emergency nursing journal, 39(4), 266-279.

10. Graham, K., \& Unger, E. (2018). Overcoming tumor hypoxia as a barrier to radiotherapy, chemotherapy and immunotherapy in cancer treatment. International journal of nanomedicine, 13, 6049.

11. Grandhige, A. P., Timmer, M., O'Neill, M. J., Binney, Z. O., \& Quest, T. E. (2016). Respiratory therapists' experiences and attitudes regarding terminal extubations and end-of-life care. 61 (7) 891-896.

12. Guo, S. E., Shen, H. C., Okoli, C., Liao, Y. C., Tsai, K. D., Lin, M. S., \& Hsu, H. T. (2018). Generalist versus specialist nurses' knowledge, attitudes, and behavioral intentions toward promoting pulmonary rehabilitation for patients with chronic obstructive pulmonary disease: A crosssectional correlational study. Medicine, 97(43.

13. Lin, Y., Zhang, X., Li, L., Wei, M., Zhao, B., Wang, X., ... \& Su, D. (2019). Highflow nasal cannula oxygen therapy and hypoxia during gastroscopy with propofol sedation: a randomized multicenter clinical trial. Gastrointestinal endoscopy, 90(4), 591601.

14. Linehan, D., \& Netzer, G. (2018). Respiratory Therapy and Family Engagement in the Intensive Care Unit. In Families in the Intensive Care Unit (pp. 315-326). Springer, Cham.

15. Mabona, J. F., van Rooyen, D. R., Jordan, P. J., \& ten Ham-Baloyi, W. (2019). Work environment in the South African military health service experienced by nurses: A qualitative study. International Journal of Africa Nursing Sciences, 11, 100171.

16. Madiha H. Bayoumi, Naglaa F. Mahmoud, (2017): Effect of education program on nurses' knowledge and practice regarding care of central venous line in pediatric hemodialysis: evidence-based practice guidelines, Egyptian Nursing Journal, Vol. 14 No. 2, P.P. :87-99.

17. Marshall, J. C., Bosco, L., Adhikari, N., Connolly, B., Diaz, J., Dorman, T., \& Vincent, J., (2017): What is an intensive care unit? A report of the task force of the World Federation of Societies of Intensive and Critical Care Medicine. Journal of critical care, 37, 270-276.

18. Mostafa, A., Mehany, M., \& Ahmed, M., (2019): Effect of Educational Program on Nurses' Knowledge and Practice About Oxygen Therapy. Assiut Scientific Nursing Journal, 7(18), 95-104.

19. Nakagami, Y., Kubo, H., Katsuki, R., Sakai, T., Sugihara, G., Naito, C., \& Hashimoto, N., (2018). Development of a 2$\mathrm{h}$ suicide prevention program for medical staff including nurses and medical residents: A two-center pilot trial. Journal of affective disorders, 225, 569-576.

20. O'Driscoll, B. R., Howard, L. S., Earis, J., \& Mak, V. (2017). British Thoracic Society Guideline for oxygen use in adults in healthcare and emergency settings. BMJ open respiratory research, $4(1$.

21. Payen, V., Zampieri, L., Porporato, P., \& Sonveaux, P., (2019): Pro-and antitumor effects of mitochondrial reactive oxygen species. Cancer and Metastasis Reviews, 38(1-2), 189-203.

22. Petersen, J., Rasmussen, L., \& RydahlHansen, S., (2017): Barriers and facilitating factors related to use of early warning score among acute care nurses: a qualitative study. BMC emergency medicine, 17(1), 36.

23. Price, S., \& Reichert, C., (2017): The importance of continuing professional development to career satisfaction and patient care: meeting the needs of novice to mid-to late-career nurses throughout their career span. Administrative Sciences, 7(2), 17.

24. Rose, J., Wang, L., Xu, Q., McTiernan, C., Shiva, S., Tejero, J., \& Gladwin, M., (2017): Carbon monoxide poisoning: pathogenesis, management, and future directions of therapy. American journal of respiratory and critical care medicine, 195(5), 596-606.

25. Rostamabadi, A., Zamanian, Z., \& Sedaghat, Z., (2017): Factors associated with work ability index (WAI) among 
intensive care units'(ICUs') nurses. Journal of occupational health, 16-0060.

26. Rupp, T., Saugy, J., Bourdillon, N., Verges, S., \& Millet, G., (2019): Positive expiratory pressure improves arterial and cerebral oxygenation in acute normobaric and hypobaric hypoxia. American Journal of Physiology-Regulatory, Integrative and Comparative Physiology, 317(5), R754R762.

27. Scala, R., \& Pisani, L., (2018): Noninvasive ventilation in acute respiratory failure: which recipe for success?. European respiratory review, 27(149), 180029.

28. Semper, J., Halvorson, B., Hersh, M., Torres, C., \& Lillington, L., (2016): Clinical nurse specialists guide staff nurses to promote practice accountability through peer review. Clinical Nurse Specialist, 30(1), 19-27.

29. Stephens, T., De Silva, A. P., Beane, A., Welch, J., Sigera, C., De Alwis, S., ... \& Abeynayaka, A. (2017). Capacity building for critical care training delivery: development and evaluation of the Network for Improving Critical care Skills Training (NICST) programme in Sri Lanka. Intensive and Critical Care Nursing, 39, 28-36.

https://www.crnm.mb.ca/uploads/ck/filesa ndards for Nursing Teaching Programs 20 July 2018.pdf at 02:15 Pm.

30. Wadia, R., Riggs, B., Goswami, D., Schwartz, J., \& Bembea, M., (2020): Pediatric Intensive Care. Gregory's Pediatric Anesthesia, 1041-1084.

31. Yousif, N., El Shinawy, O., Daef, E., \& ElShafiey, O., (2020): Designed Education Program for Nurses about Immediate and Long Term Nursing Management of Patient with Status Asthmaticus in El-Mobara Hospital at Assiut Governorate. Assiut Scientific Nursing Journal, 8(20), 141-154. 